Article

\title{
The Digital Integrated Workflow in the Aesthetic Management of the Smile: A Case Report
}

\author{
Paolo Scattarelli ${ }^{1}$, Paolo Smaniotto ${ }^{2,3}$, Serena Leuci ${ }^{1}$, Gabriele Cervino ${ }^{4, *}$ and Mario Gisotti ${ }^{1}$ \\ 1 Private Practice Bitonto, 70023 Bari, Italy; paolo.scattarelli@libero.it (P.S.); leuci.serena@libero.it (S.L.); \\ mariogisotti@gmail.com (M.G.) \\ 2 Private Practice Bassano del Grappa, 36061 Vicenza, Italy; info@labsmaniotto.com \\ 3 Prosthetic Technologies Laboratory, University Vita Salute San Raffaele, 20132 Milan, Italy \\ 4 Department of Biomedical and Dental Sciences, Morphological and Functional Images, \\ University of Messina, Policlinico G. Martino, Via Consolare Valeria, 98100 Messina, Italy \\ * Correspondence: gcervino@unime.it
}

Received: 15 July 2020; Accepted: 14 August 2020; Published: 18 August 2020

check for updates

\begin{abstract}
The aesthetic treatment for anterior teeth requires a series of clinical and technical evaluations to obtain a predictable result, following a well-defined operating sequence. Today, the clinical-technical team can use different digital tools in the different steps of the workflow. A preventive assessment, the knowledge of limits, and the possibilities of surgical and prosthetic procedures allow to use these devices. Sharing goals of the treatment with the patient according to their expectations and needs is the key point of the treatment plan. Setting a defined treatment plan avoids invasive procedures. In this clinical case report, a 27-year-old patient affected by Class II div 2 malocclusion with deep bite was treated with a full digital workflow. Previewing the aesthetics was through dedicated software, which shows operators and patients the objectives of the therapy and guides the dental technician in the first phase of the work. The use of digital flows in the prosthetic phases reduces the working time. In this case, it shows the impact of a digital workflow on peri-prosthetic therapy for the aesthetic rehabilitation of the upper central incisors in a young adult.
\end{abstract}

Keywords: Digital Smile Design; restorative dentistry; dentistry software; dentistry design

\section{Introduction}

The current objectives of a fixed prosthesis are aimed at achieving a harmonious integration of the dental crown into the patient's stomatognathic system at the same time as adequate long-term rehabilitation.

The achievement of clinical success is strongly influenced by the materials, the innovative techniques available to us, an adequate clinical evaluation, and timely therapeutic planning.

The constant request for an aesthetic result has also stimulated research into the use of materials for prosthetic rehabilitation integrated with the surrounding tissues.

The continuous experimental research and the evolution of techniques and materials has therefore transformed the prosthesis, a sector of dentistry, existing since ancient times.

Today digital is an established and confirmed reality in the daily life of the society in which we are immersed, and therefore a digital dental workflow has become a professional element within the reach of all operators in the sector [1].

The new processing software, for example, aims to make the entire rehabilitation work flow digital, simplifying the work of the professional and also facilitating communication with the patient. A quick search on the main computer engine indicates all the software available on the market, among which an important role is undoubtedly the method of a Digital Smile Design. 
This software allows for excellent communication with the patients, offering the clinician a tool to make the correct therapeutic choice through algorithms [2].

The fundamental parts of this method are the detailed analysis of the smile and its design, indispensable for the formulation of an aesthetic clinical case.

The first step involves the acquisition of images and videos (static and dynamic dental face); the import of these fundamental data into the patient's digital aesthetic file will be complementary to the anamnesis, since they are an integral part of the intra- and extra-oral exam.

The second step involves the aesthetic analysis according to the main guidelines. The dynamic smile analysis and dento-labial phonetic analysis are identified through their characteristics, recording the images captured during rest, speech, and smile, thus allowing a better understanding of the variations in the perioral soft tissues. The Smile Design is a useful way of communicating to the patient the "idea" through visual information of what the new aesthetic composition of the smile will be like, synonymous with predictability, and an excellent tool to be inserted in the $360^{\circ}$ communicative language, especially with the dental team. The modeling and positioning give the appearance and the three-dimensional visual perception of the morphology of the teeth, which the dental team will have to copy during the CAD design modeling phase.

In this clinical case we analyzed the aesthetic treatment for anterior teeth using different tools in the different steps of the workflow [3]. Previewing the aesthetics was through dedicated software and shows the operators and patients the objectives of the therapy and guides the dental technician in the first phase of the work [4].

The use of a digital workflow in the prosthetic phases reduces working time [5]. In this case, it shows the impact of a digital workflow on peri-prosthetic therapy for the aesthetic rehabilitation of the upper central incisors in a young adult.

\section{Materials and Methods}

\section{Case Report}

A patient of 27 years old required an improvement of his smile in a very short time, eliminating the presence of the diastemas. The dento-facial analysis reveals a gummy smile and a $4 \mathrm{~mm}$ dental exposure of the upper central incisors. The patient shows diastemas in the upper frontal group and a disto-rotation of the right central incisor. Besides an accentuated overbite, the occlusion is regular with an incisive protrusive guide and lateral canine guide. No symptoms referred to the ATM (temporomandibular articulation). Gingival analysis shows asymmetric gingival parables of 1.1 and 1.2 elements compared to 2.1 and 2.2, caused by an altered passive eruption. The aesthetics parameters established that the upper central incisors' parables have to be $0.5-1 \mathrm{~mm}$ more apical than those of the lateral incisors [6].

For the realization of the clinical case in question, the team opted for the use of an innovative dental preparation design for ceramic veneers called the "self-centering geometric preparation". The inspiring principle on which the technique is based is linked to a purely geometric concept; that is, to exploit the orientation of the opposite walls with a known angle $\left(30^{\circ}\right)$ capable of imparting a unique positioning to the product during the cementing phase, following the same self-centering principle, thus exploiting the possibility of cementing the artefact following an axis perpendicular or slightly oblique to the buccal surface of the dental element and not along the major axis, minimizing problems such as the fracture of the artifact or poor positioning of the same during the delicate cementation phase. The self-centering geometric preparation consists of two surfaces (mesial and distal) with an inclination of thirty degrees and an incisal butt-joint design in order to impart a self-centering morphology to the dental preparation. The choice of the ideal finish line in the cervical area will be managed by the prosthetist: a horizontal preparation, a vertical preparation, or a no-prep.

The first step of the treatment plan is the diagnosis, including a full arch optical impression (Trios 3Shape ${ }^{\circledR}$, 3Shape A/S, Copenhagen K, Denmark), the evaluation of the intermaxillary relationships, 
photos, full mouth X-rays, and PSR (Periodontal Screening Recording). Based on these indications, the dental technician performed a diagnostic wax-up with a CAD-CAM system $\left(\right.$ Exocad $^{\circledR}$, exocad America, Inc., Darmstadt, Germany).

In the second step, the realization of the Digital Smile Design offers to the patient different care options. The ideal treatment plan is an orthodontic treatment; if this is refused by the patient, the choice is for a resective surgery of 1.1 and 1.2 elements and the realization of four veneers for the closure of the diastemas.

The third step is the surgical phase with the goal of harmonizing the gingival margin incisal profiles. On these elements the presence of short crowns, confirmed by intraoral X-rays, shows the altered passive eruption classified as type B, subgroup 1 according to Coslet [7]. A surgical template, obtained from the digital diagnostic wax-up, is a guide for the first gingivectomy (1.1 and 2.2). After lifting a full thickness flap of $3 \mathrm{~mm}$ beyond the ridge, they proceed with osteoplastic and osteotomy surgery, with manual and rotating instruments in order to realize an armory of the smile. The flap is subsequently sutured by a vertical mattress suture with PTFE 5/0. The suture will be removed 15 days after the intervention.

The fourth step: 12 months after the surgery, the four veneers are prepared with the mock-up drilling technique. The prosthetist calibrates the required space for future manufactures by printing on the teeth, not yet prepared, the diagnostic wax-up using a silicone mask and a self-curing resin. With this technique it is possible to remove the least dental tissue according to the type of material and also to the final volume that we want to obtain. During the same session, the preparations are scanned after an appropriate retraction of the gingival margins to expose the finishing line and to apply the provisional teeth. The dental laboratory receives the scanned files almost simultaneously. The matching allows then the overlapping of the virtual diagnostic wax-up to the scans of the preparations and the provisional veneers. The modeling of the veneers can be made by CAD, controlling the shape of the provisional model and the space between each tooth. The assembly in a virtual articulator avoids the harmful precontacts. The calibrated removal of the superficial layers of the manufact allows to make space for the vestibular stratification with veneering ceramic. A scanning prototype is realized through the die casting technique, which is duplicated in lithium disilicate. In the fifth and final session, the veneers are tested by trial cements to evaluate their fitting and color and then cemented. The cementation technique is made by conditioning both the ceramic material and the dental surface to have a high adhesion value. In this specific case, the internal surface of the veneers is treated with $9 \%$ hydrofluoric acid for $20 \mathrm{~s}$, then rinsed and immerged in an ultrasound bath with pure alcohol for $3 \mathrm{~min}$. After drying, the silane is applied and then evaporated with a heat source and bonding. The dental surface is cleaned by rubbers and airflow with erythritol powders, etched with $35 \%$ orthophosphoric acid for $15 \mathrm{~s}$ and the bonding applied. The cementation, under the dam and retraction threads to contain the cement spill is made by light-curing nanohybrid cement (Figures 1-26).

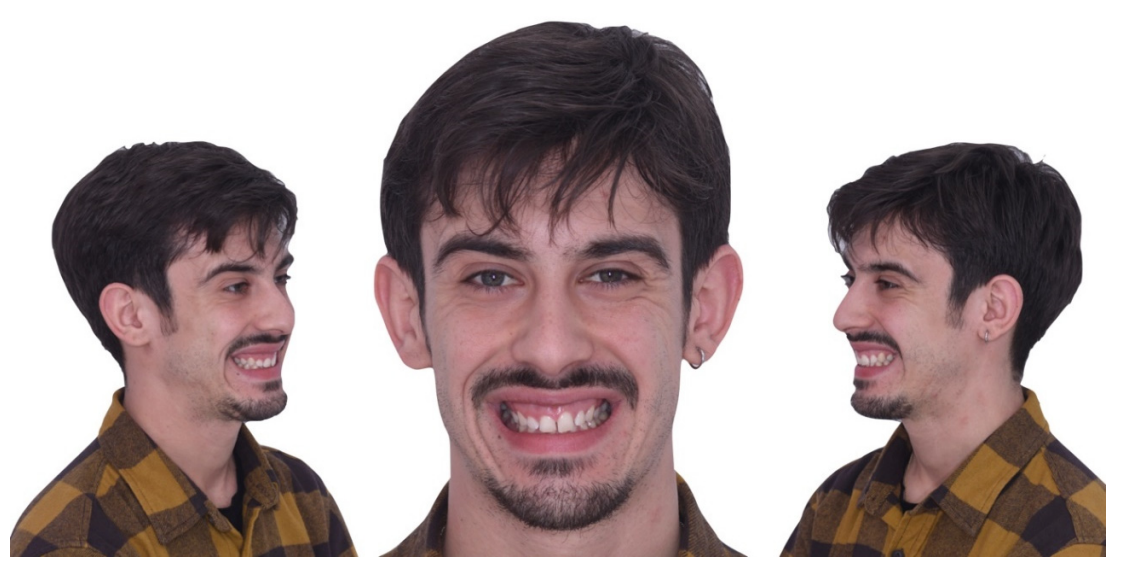

Figure 1. Preoperative extraoral vision. 


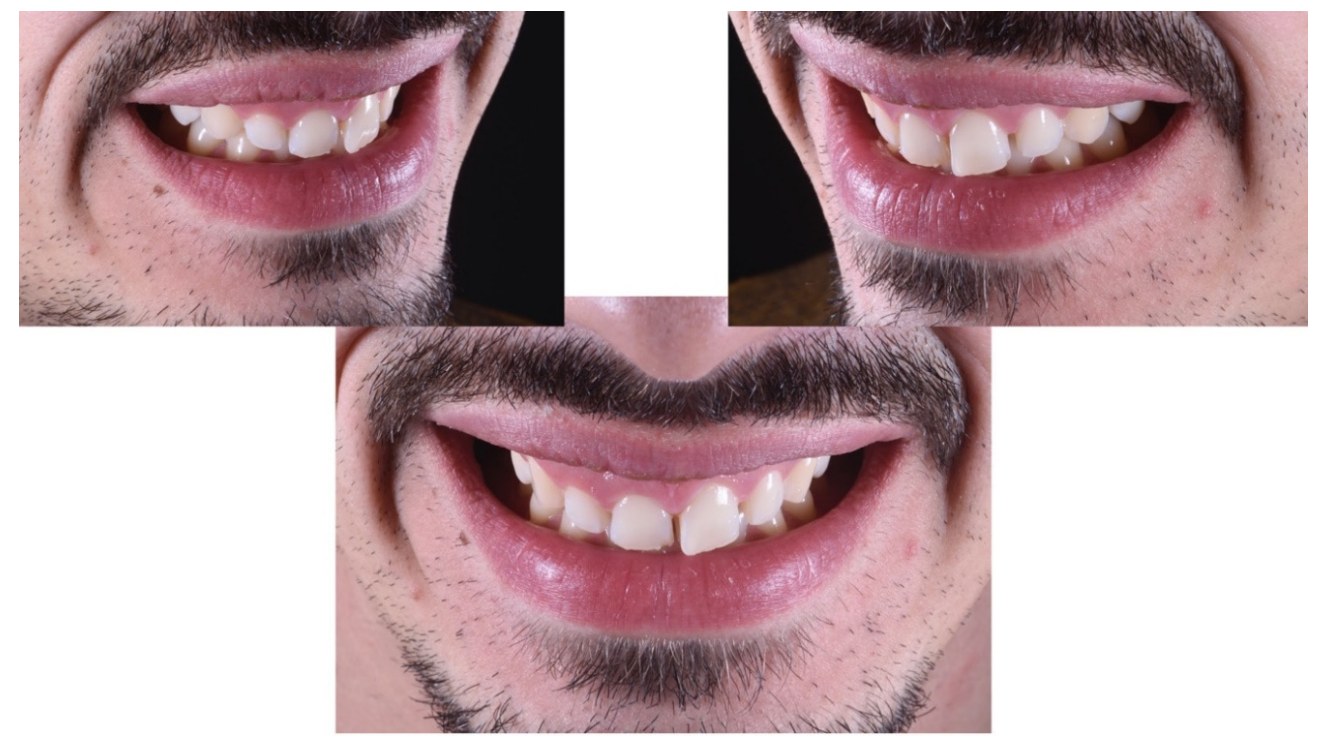

Figure 2. Intraoral preoperative vision.

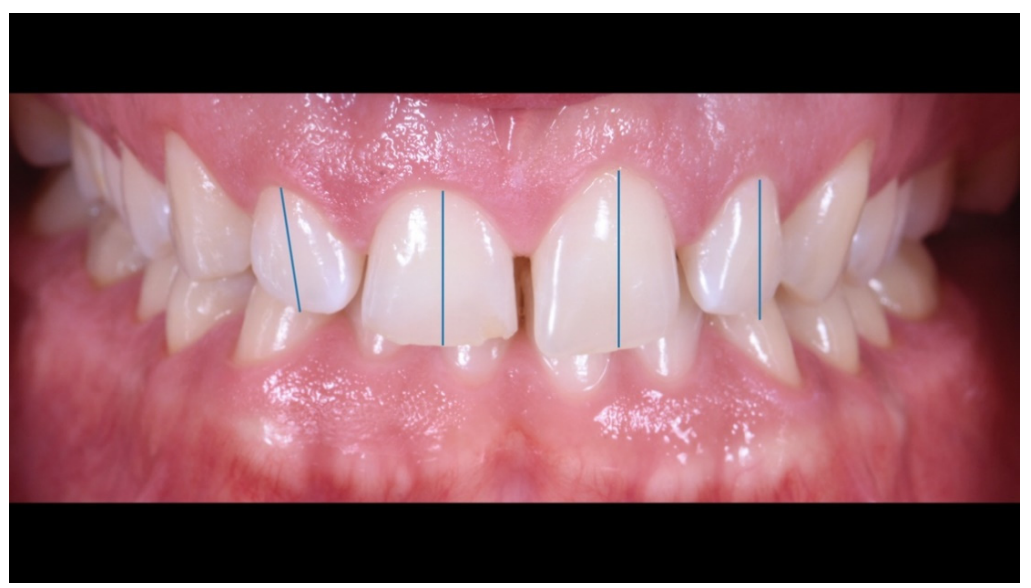

Figure 3. Asymmetry and mesialization of the dental axes in the upper frontal group.

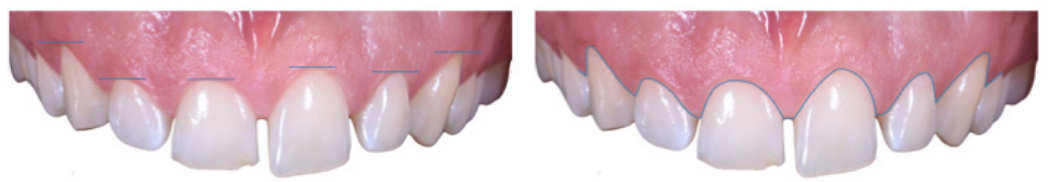

Figure 4. Asymmetry of the gingival parables in the second sextant.

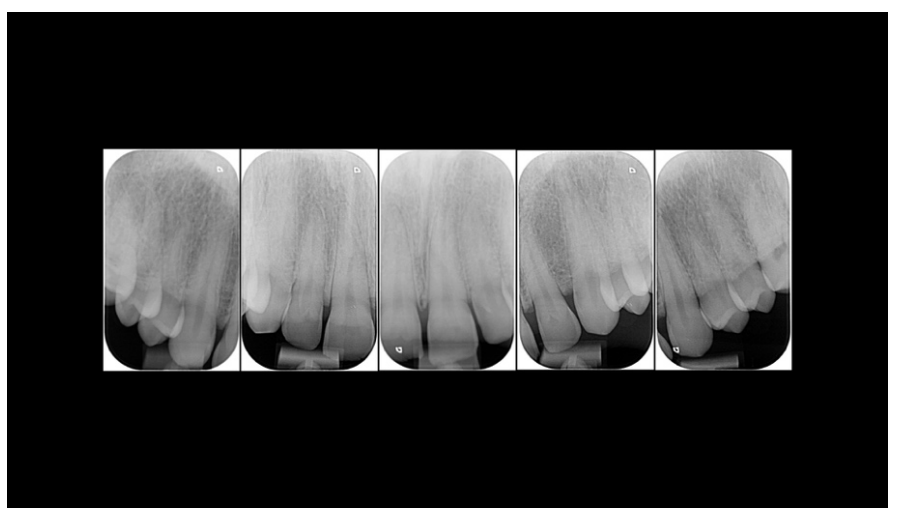

Figure 5. Intraoral radiographs. 


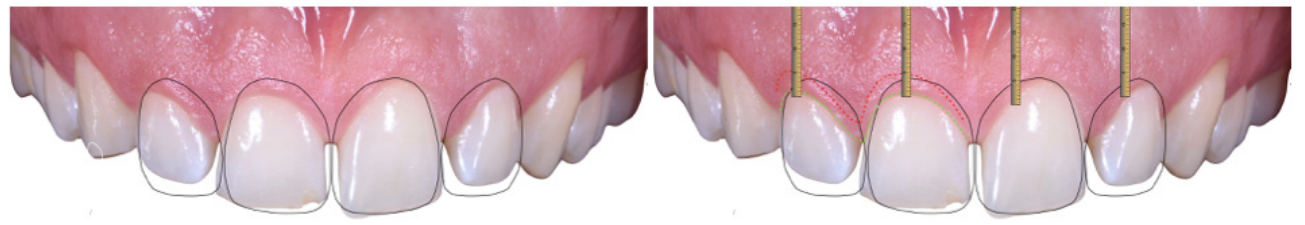

Figure 6. Digital Smile Design and calibration of the new dental forms.
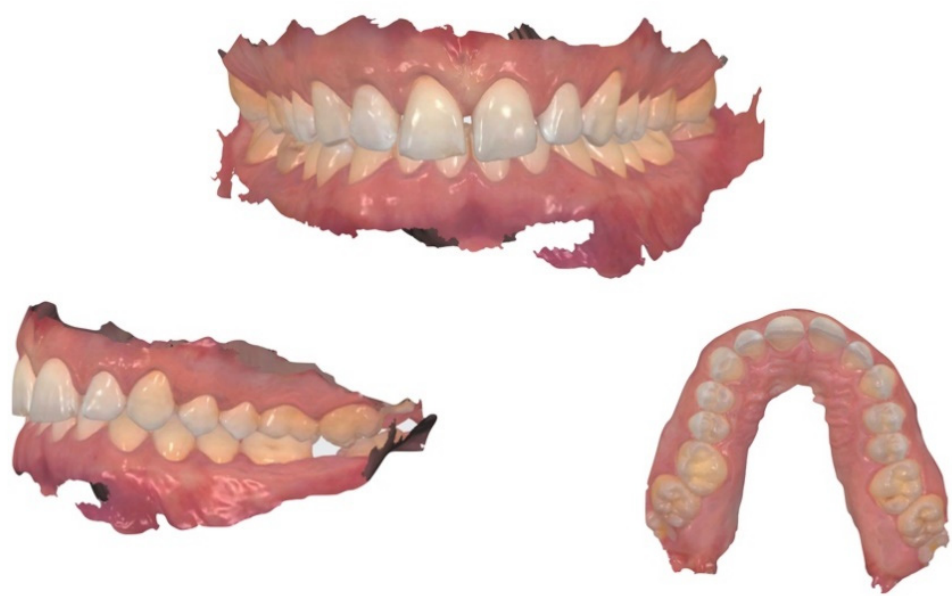

Figure 7. Intraoral scan.

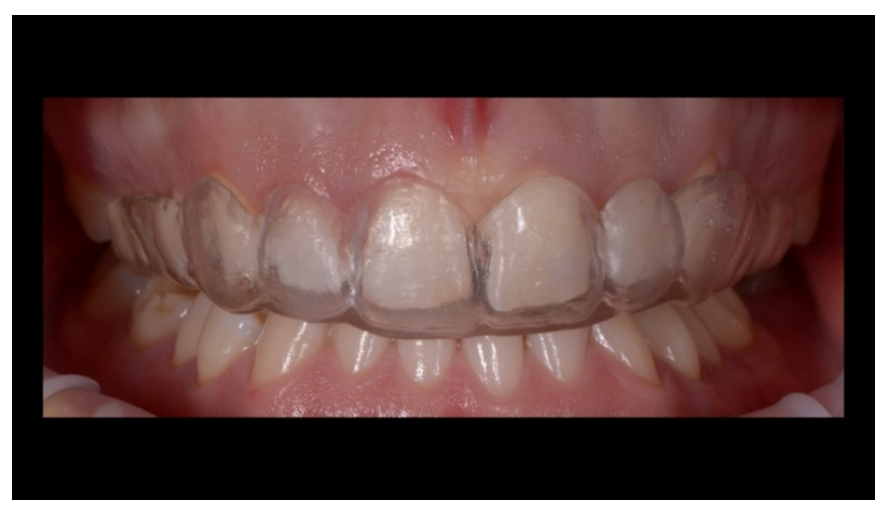

Figure 8. Test of the surgical template for the gingivectomy planned for increasing the volume of the teeth crown.
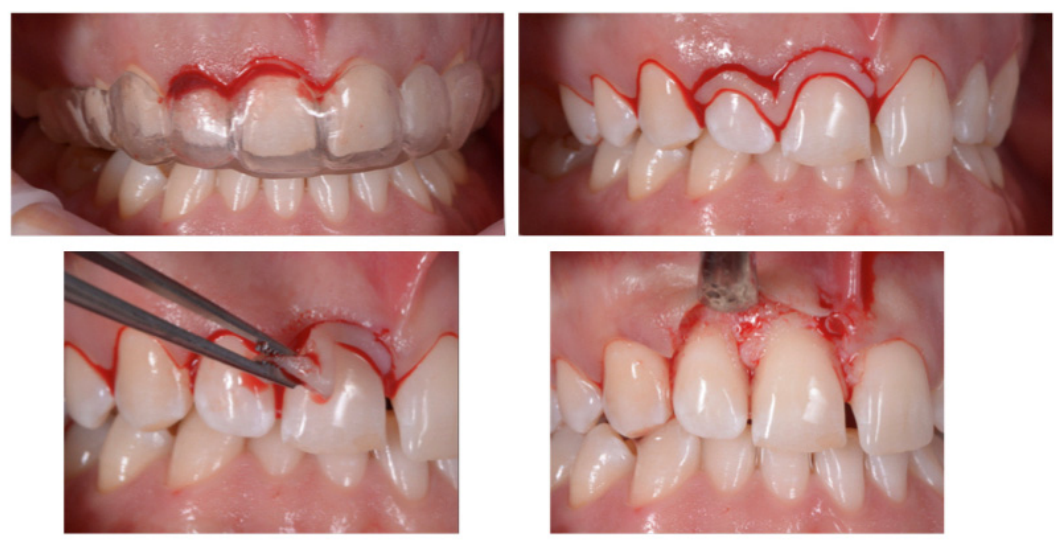

Figure 9. Paramarginal incision guided by the template resulting from the diagnostic wax-up. 

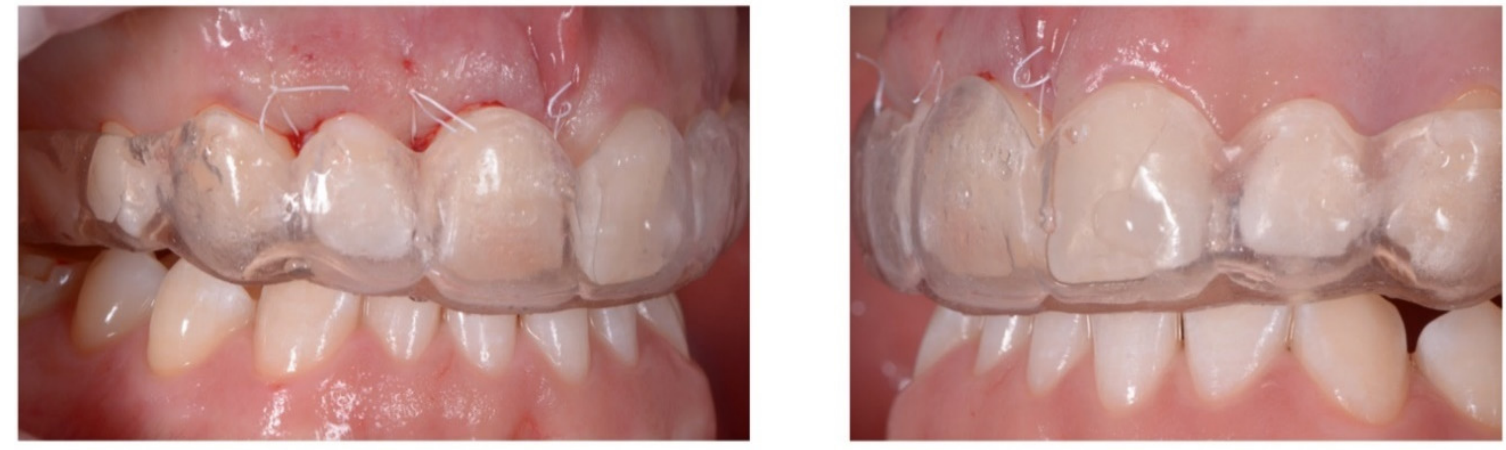

Figure 10. Suture and verification of the new position of the gingival parables.

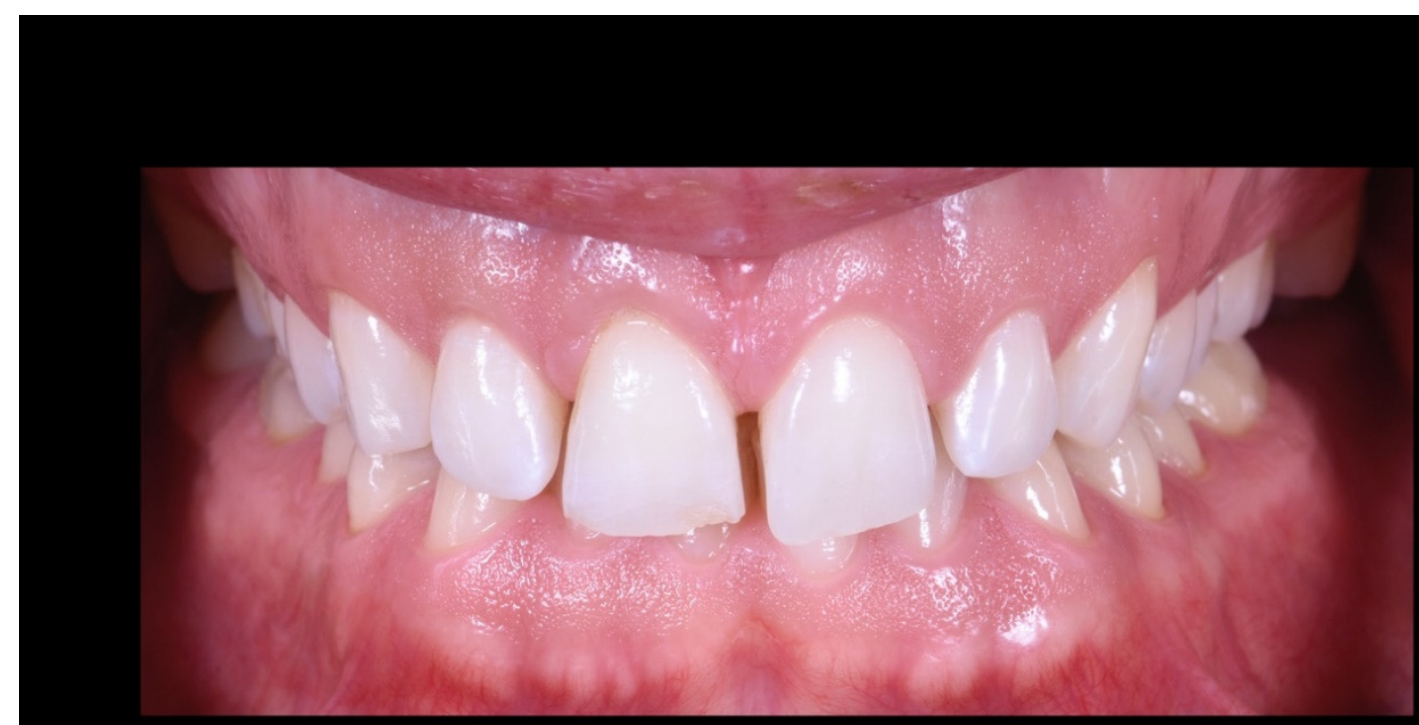

12 MONTHS POST OP
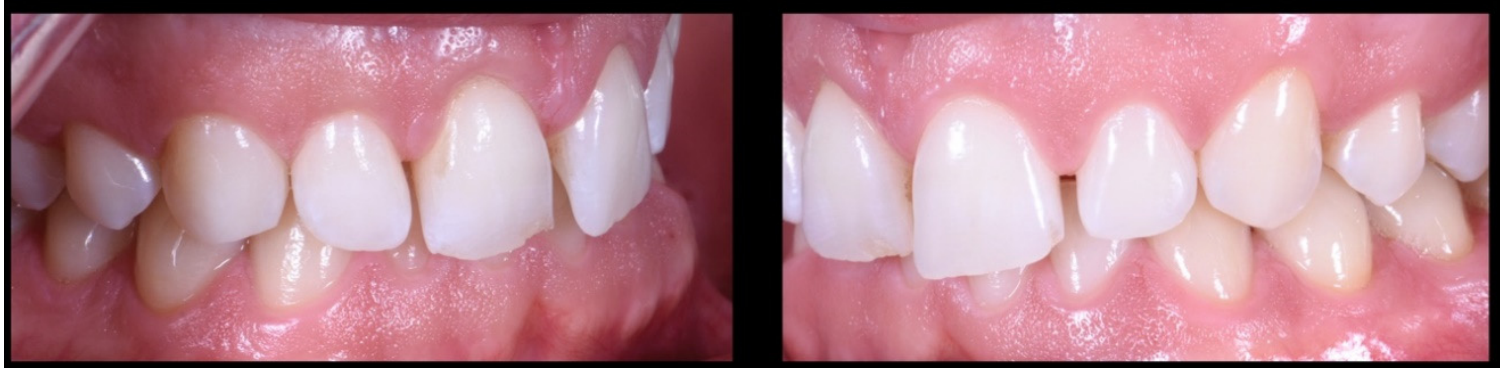

Figure 11. Periodontal tissues 12 months after surgery. 


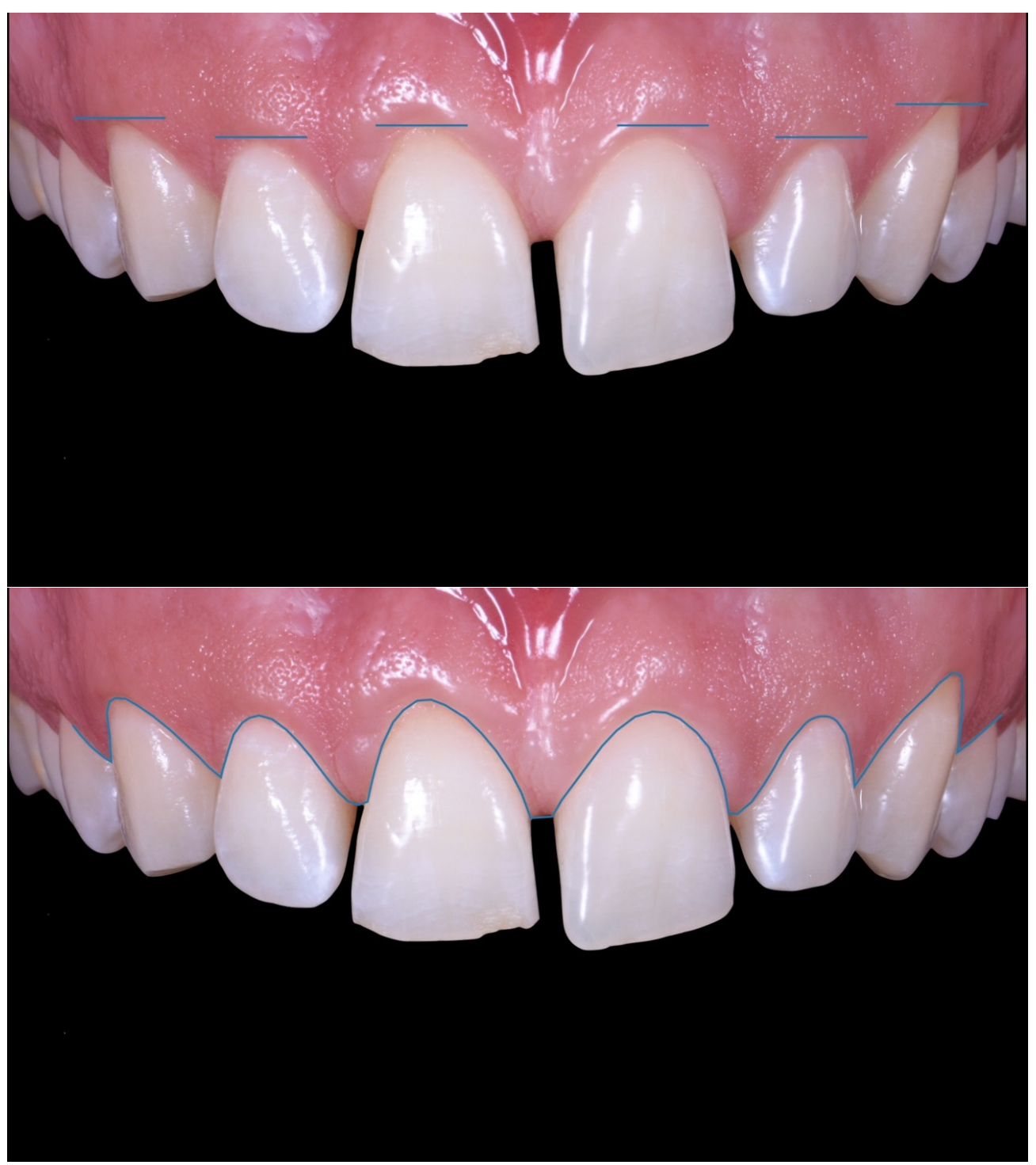

Figure 12. Symmetry of the gingival levels in the upper frontal sector.

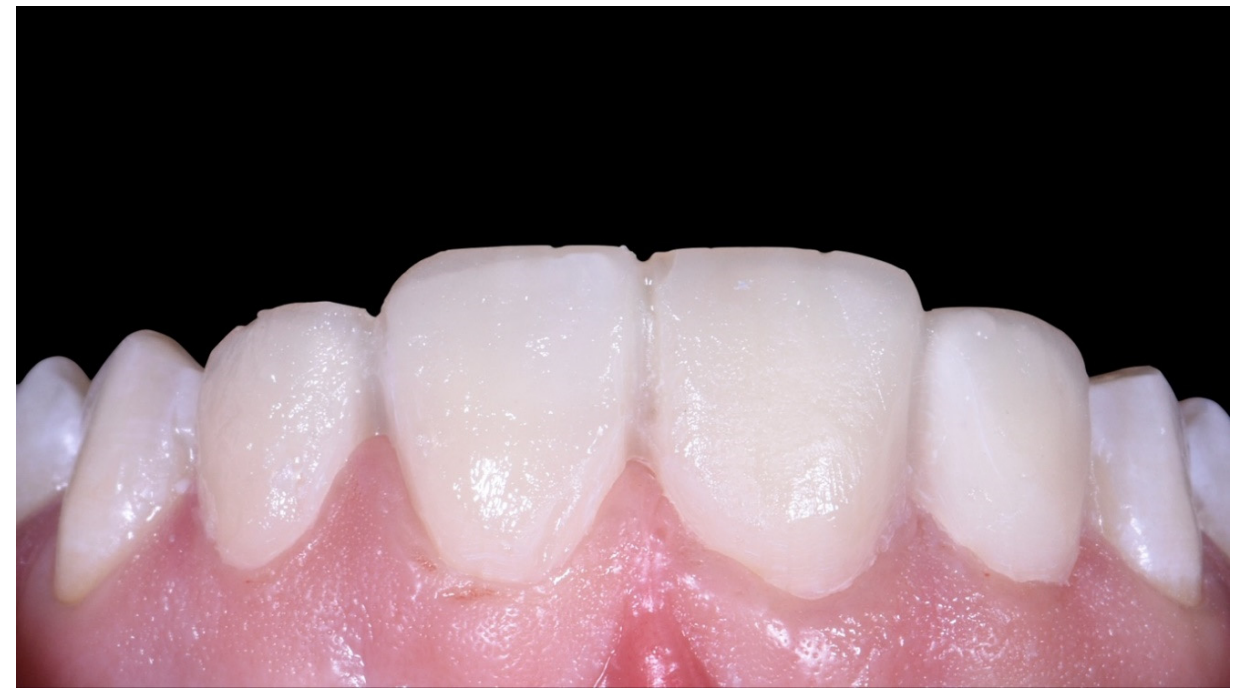

Figure 13. Mock-up for the veneers on the central incisors. 


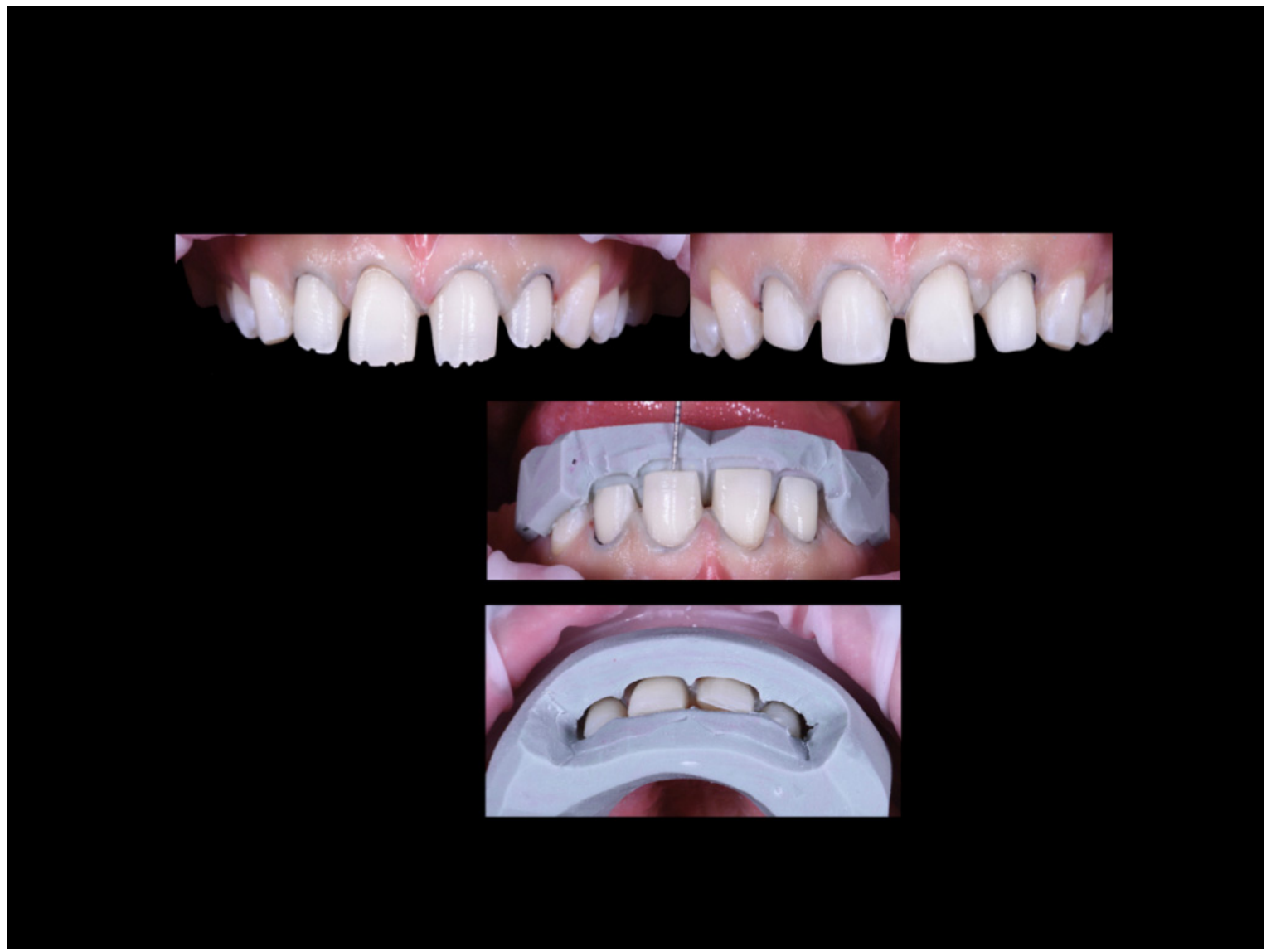

Figure 14. Dental preparation for the veneers guided by silicone masks.

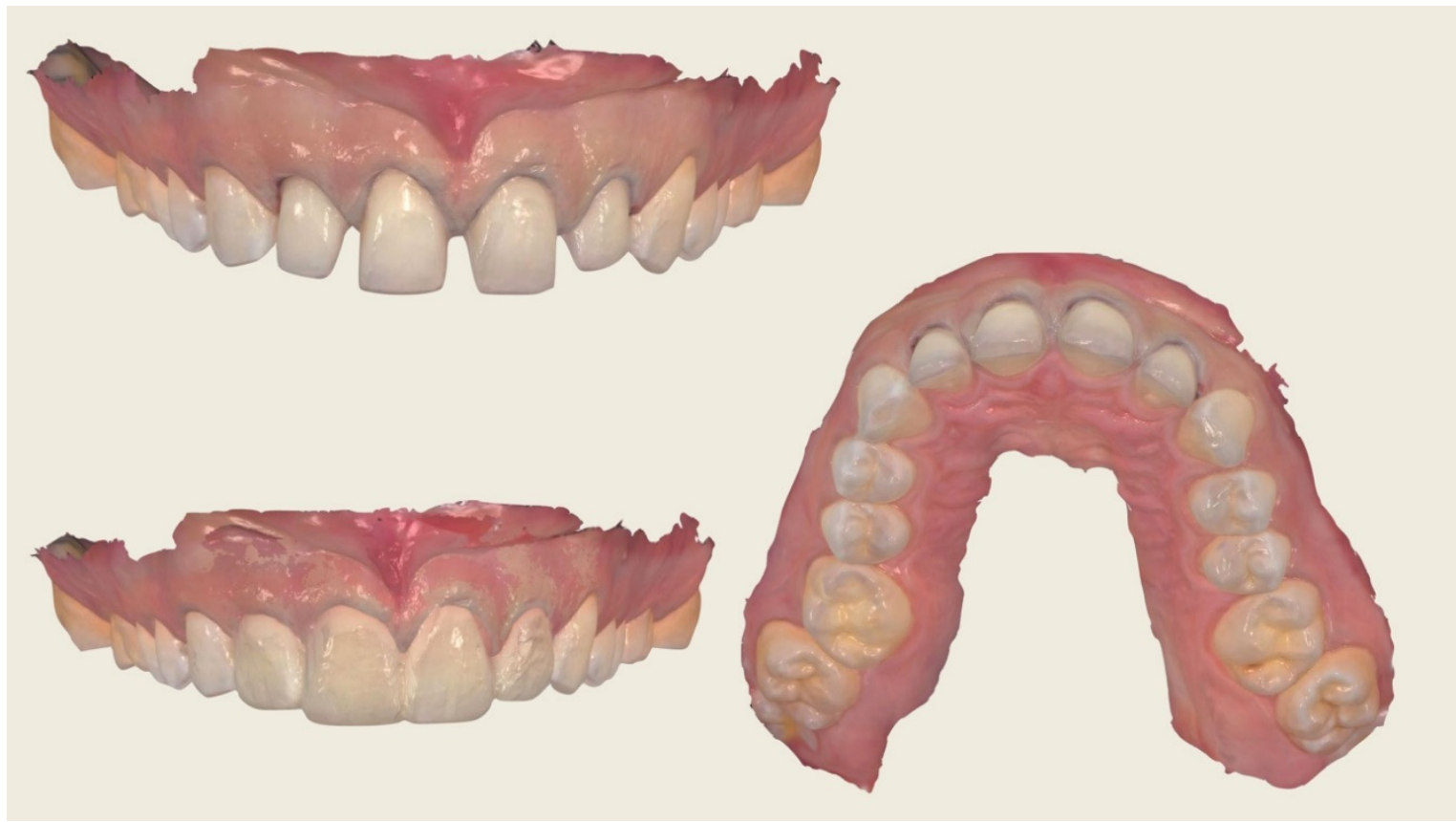

Figure 15. Intraoral scan. 

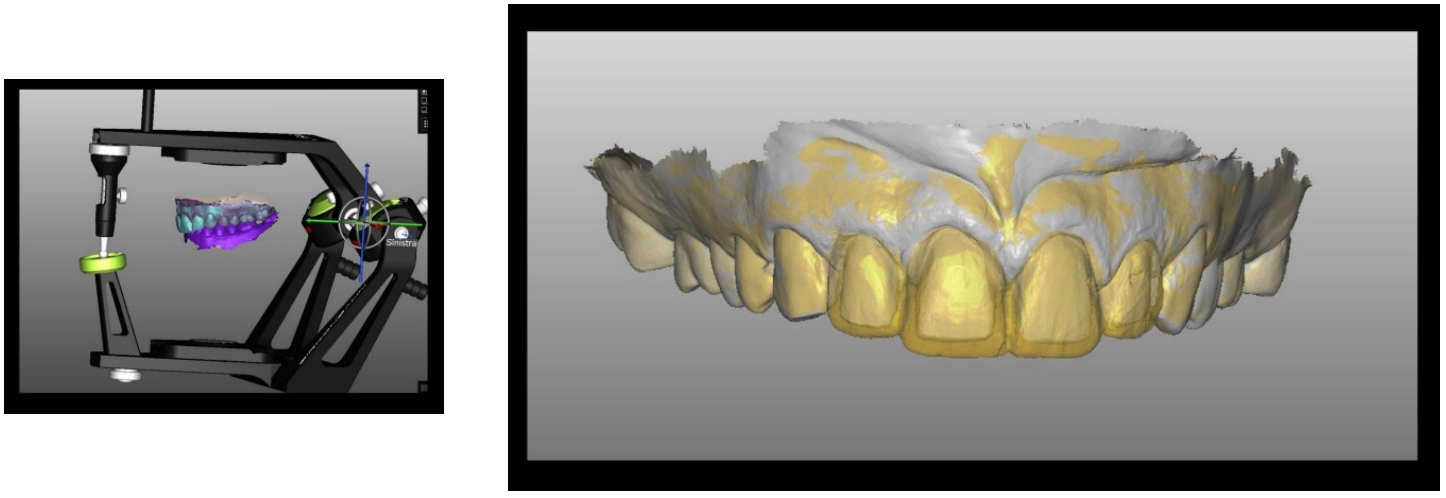

Figure 16. CAD fabrication of the PMMA (Poly Methyl Methacrylatemethacrylic Acid) temporaries.

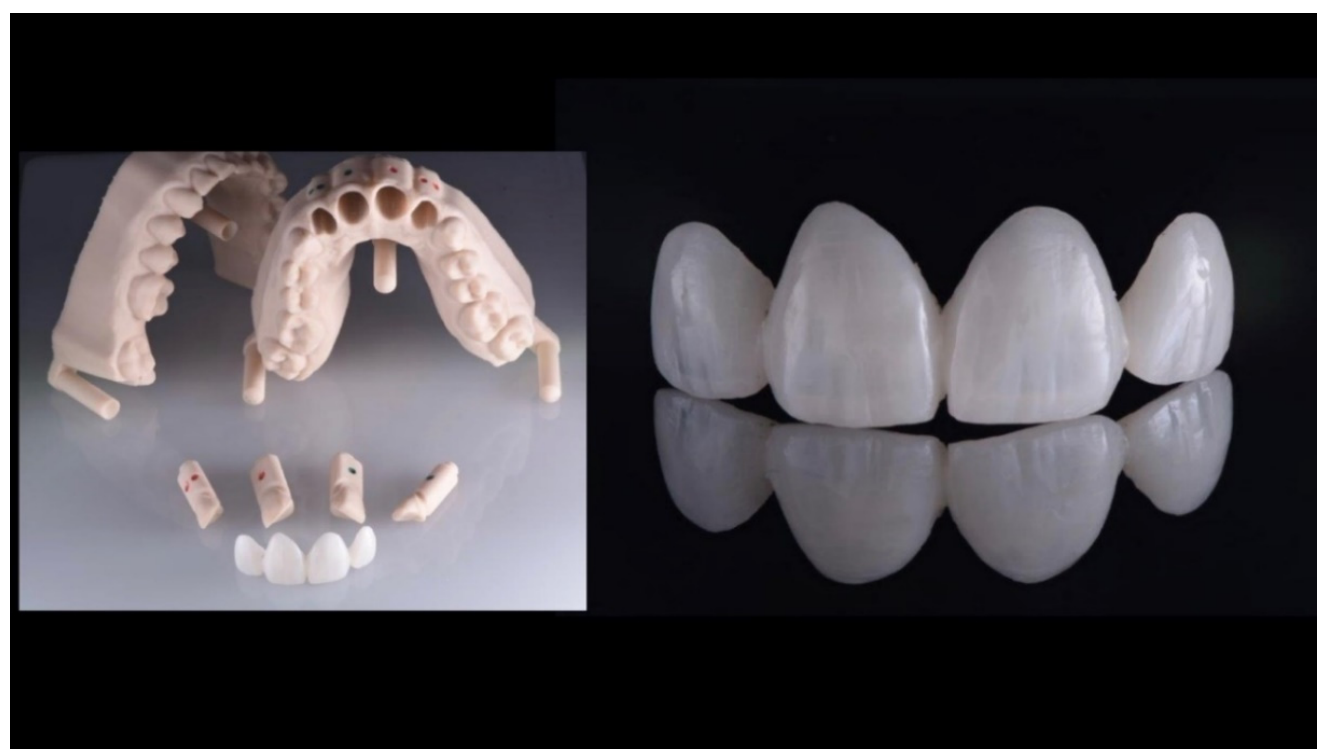

Figure 17. Temporaries on a stereolithographic model.

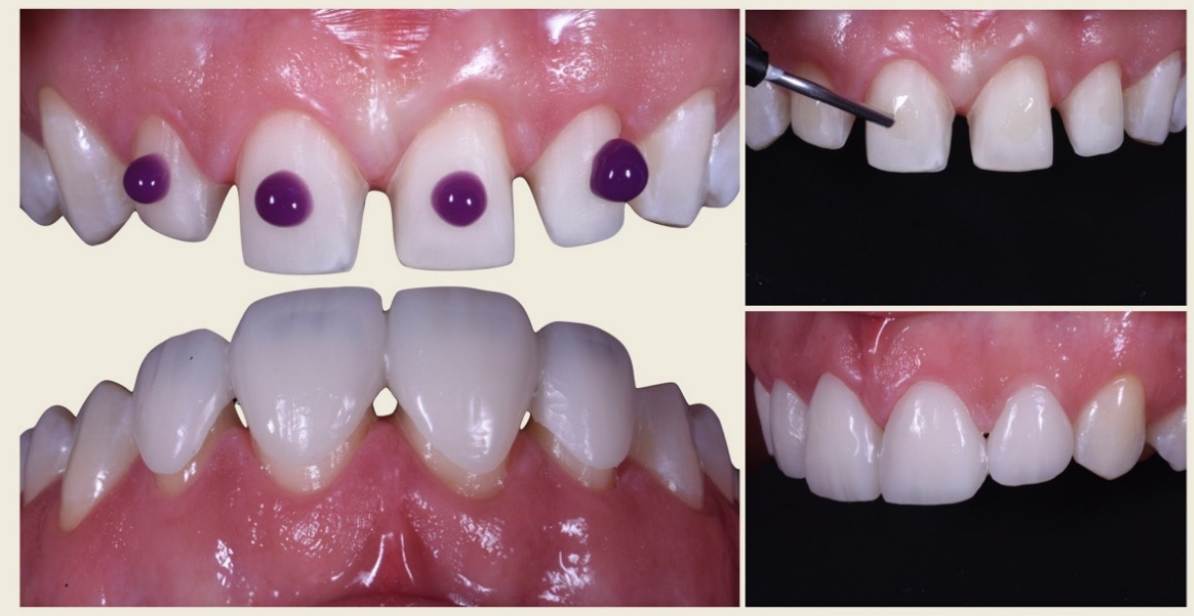

Figure 18. Temporary cementation. 


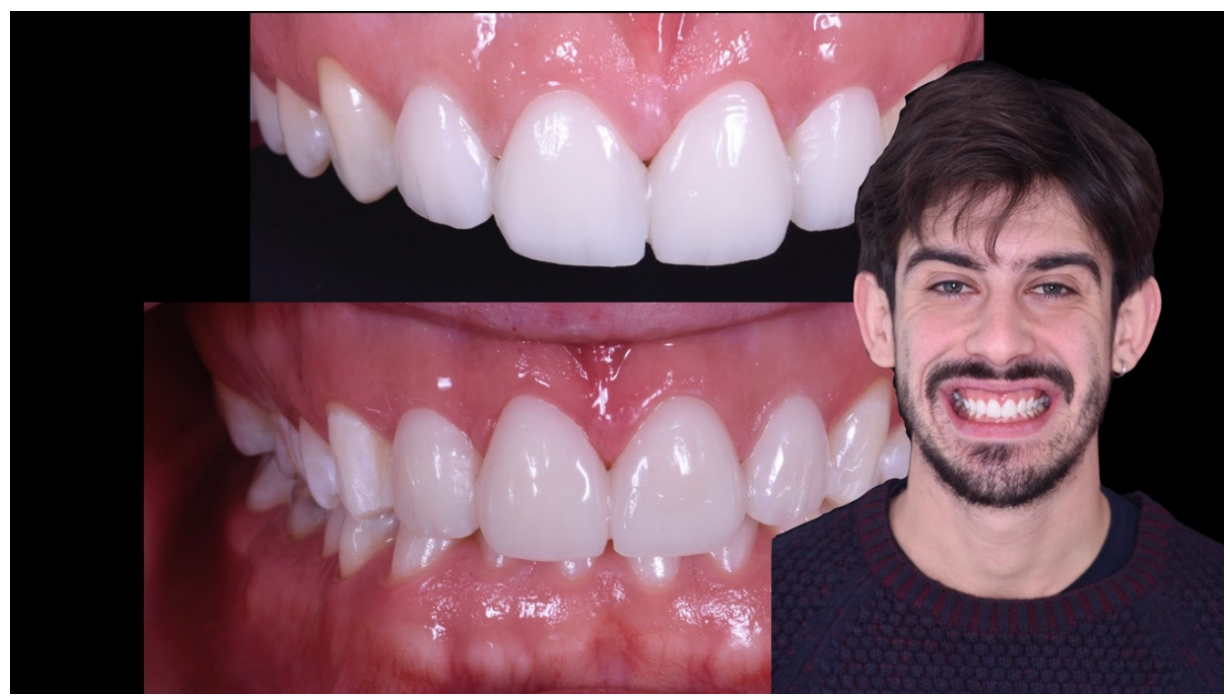

Figure 19. Aesthetic integration of the provisionals.

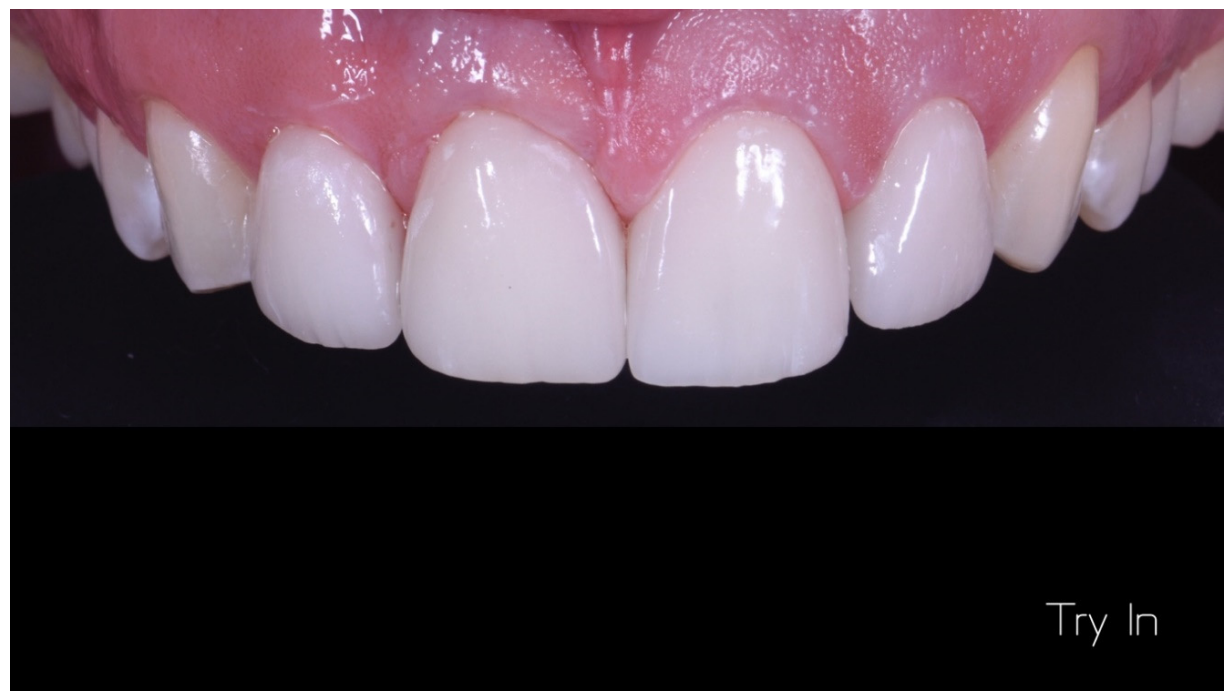

Figure 20. Try on the lithium disilicate veneers.

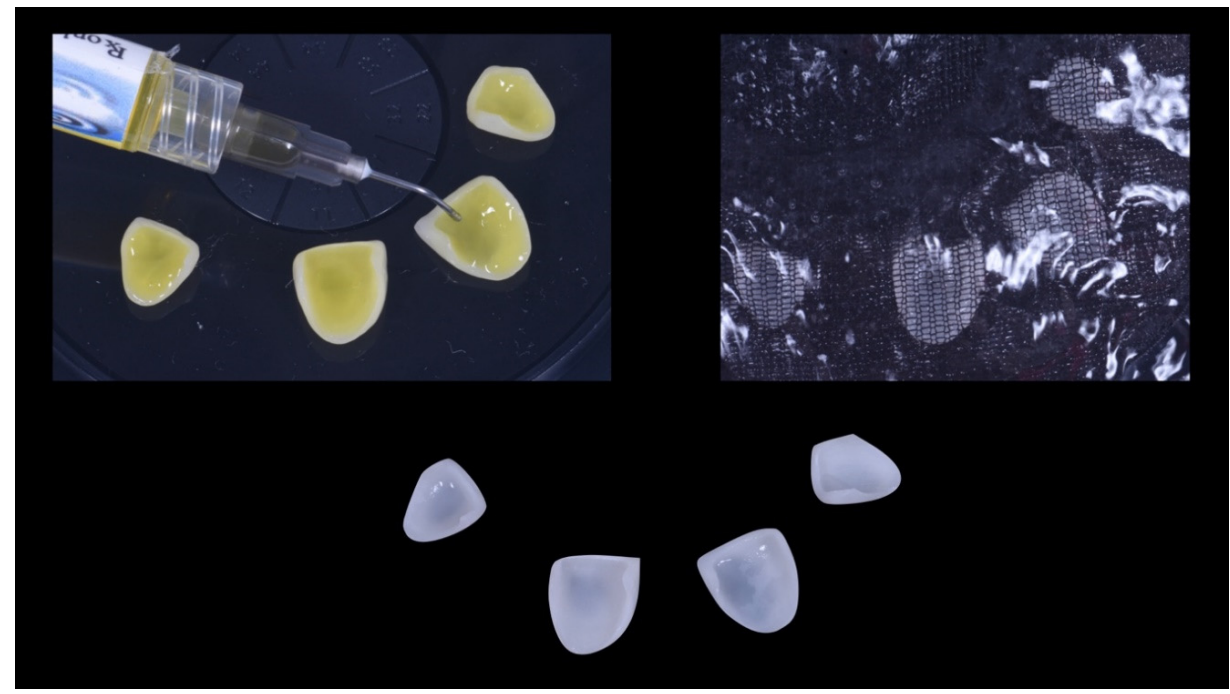

Figure 21. Treatment of the veneers with hydrofluoric acid. 


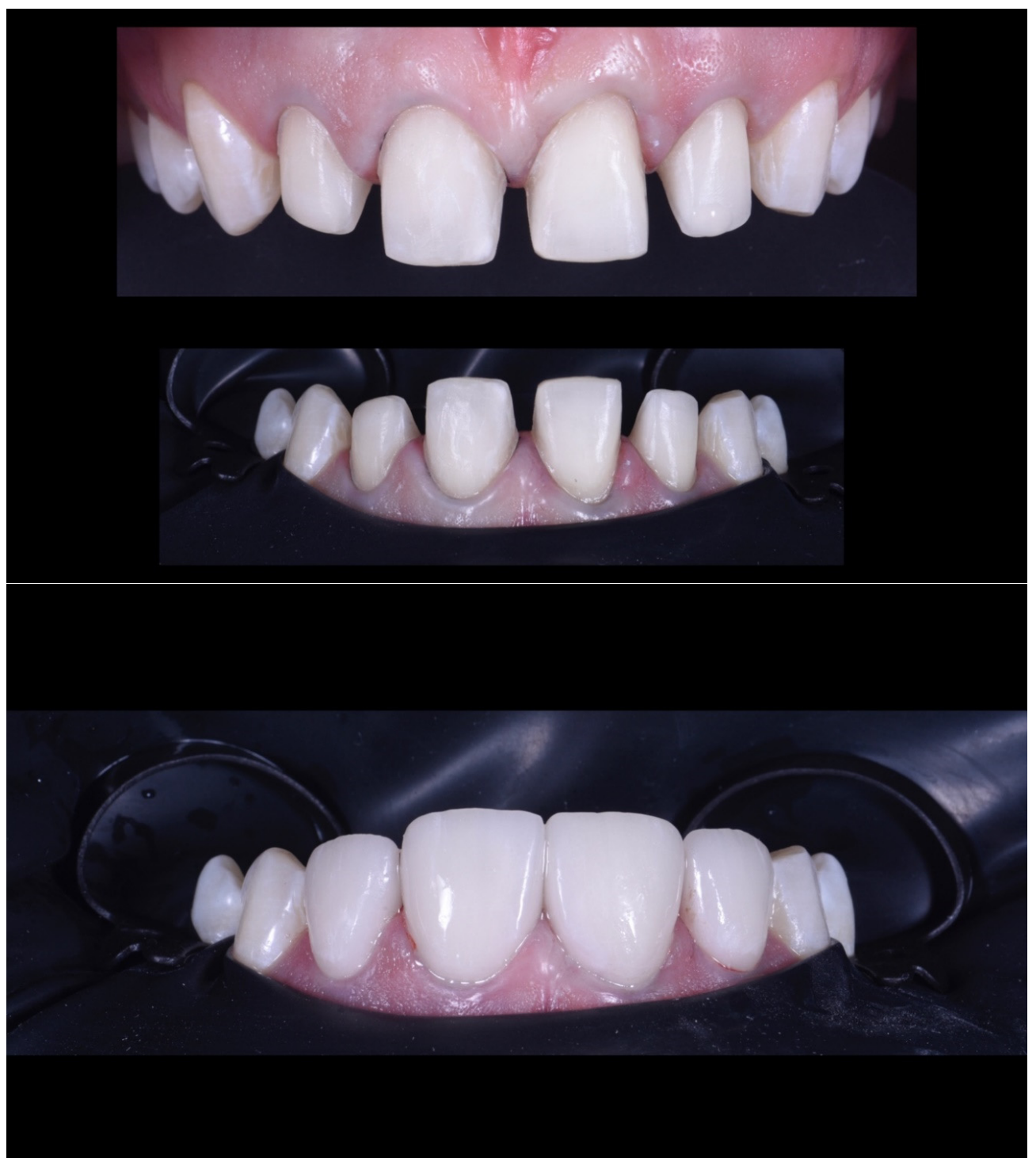

Figure 22. Bonded veneer.

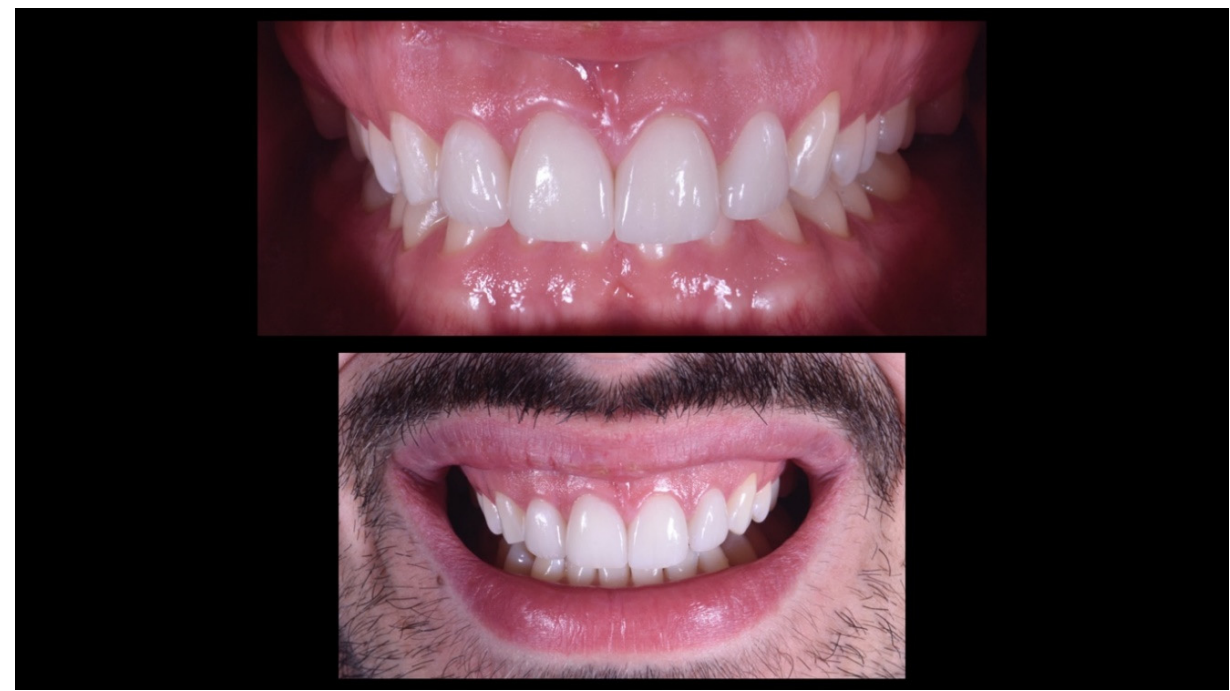

Figure 23. Aesthetic and functional integration. 

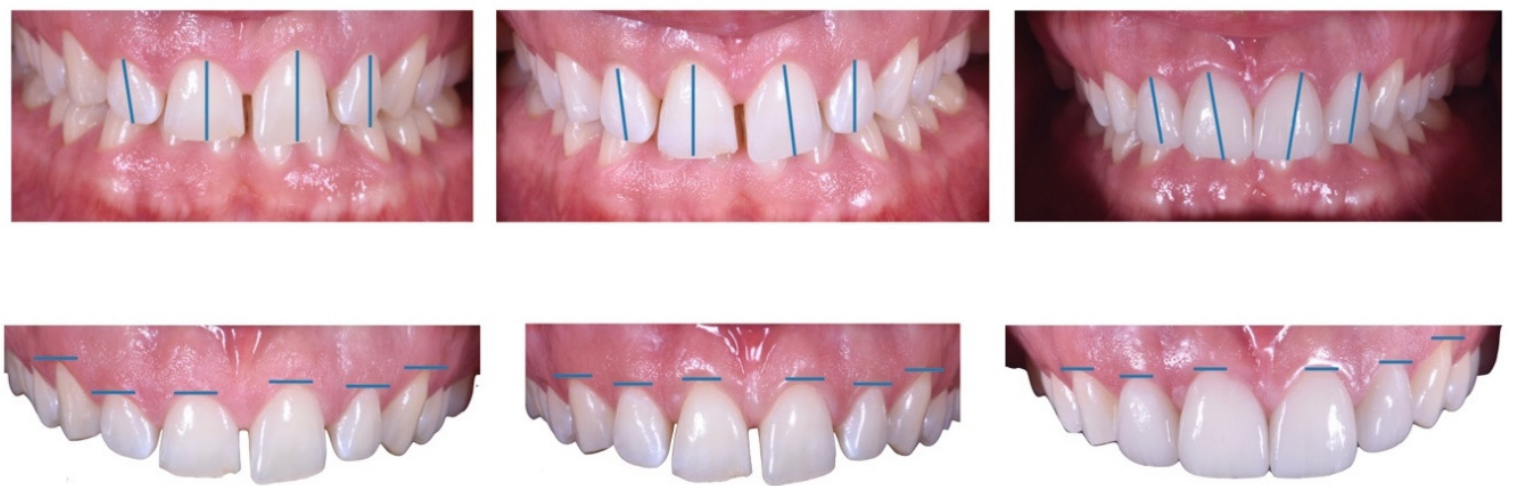

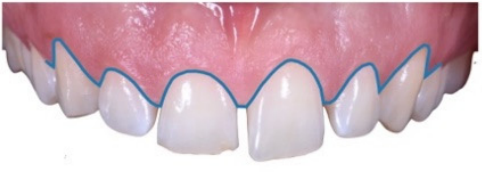

TO

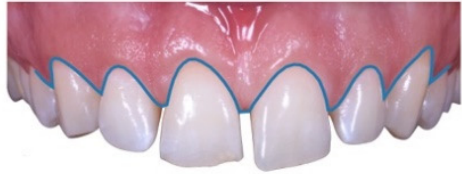

T12

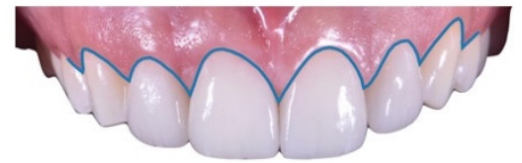

T24

Figure 24. Change of dento-periodontal relationships during the peri-prosthetic treatment.

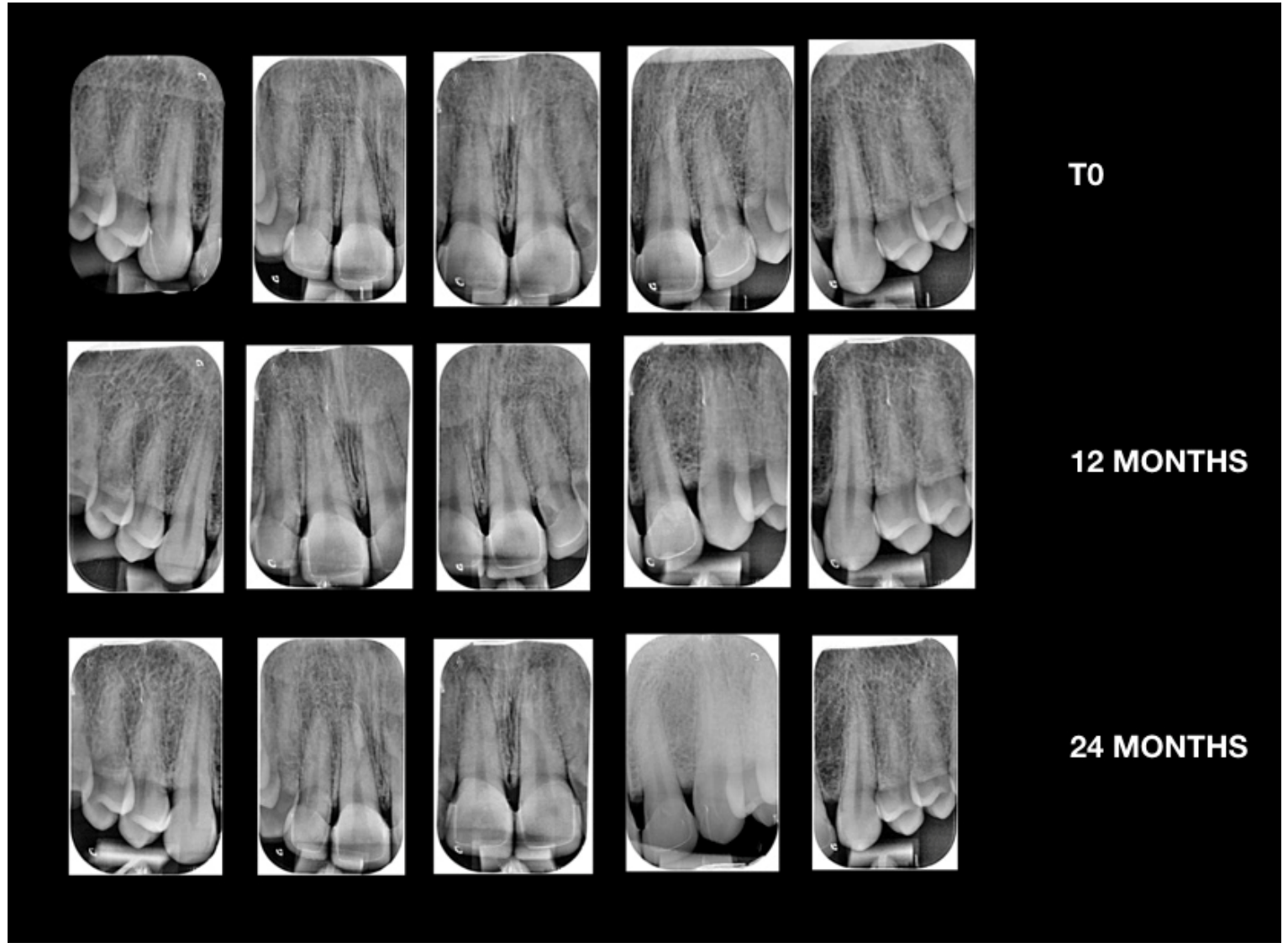

Figure 25. X-ray investigation. 


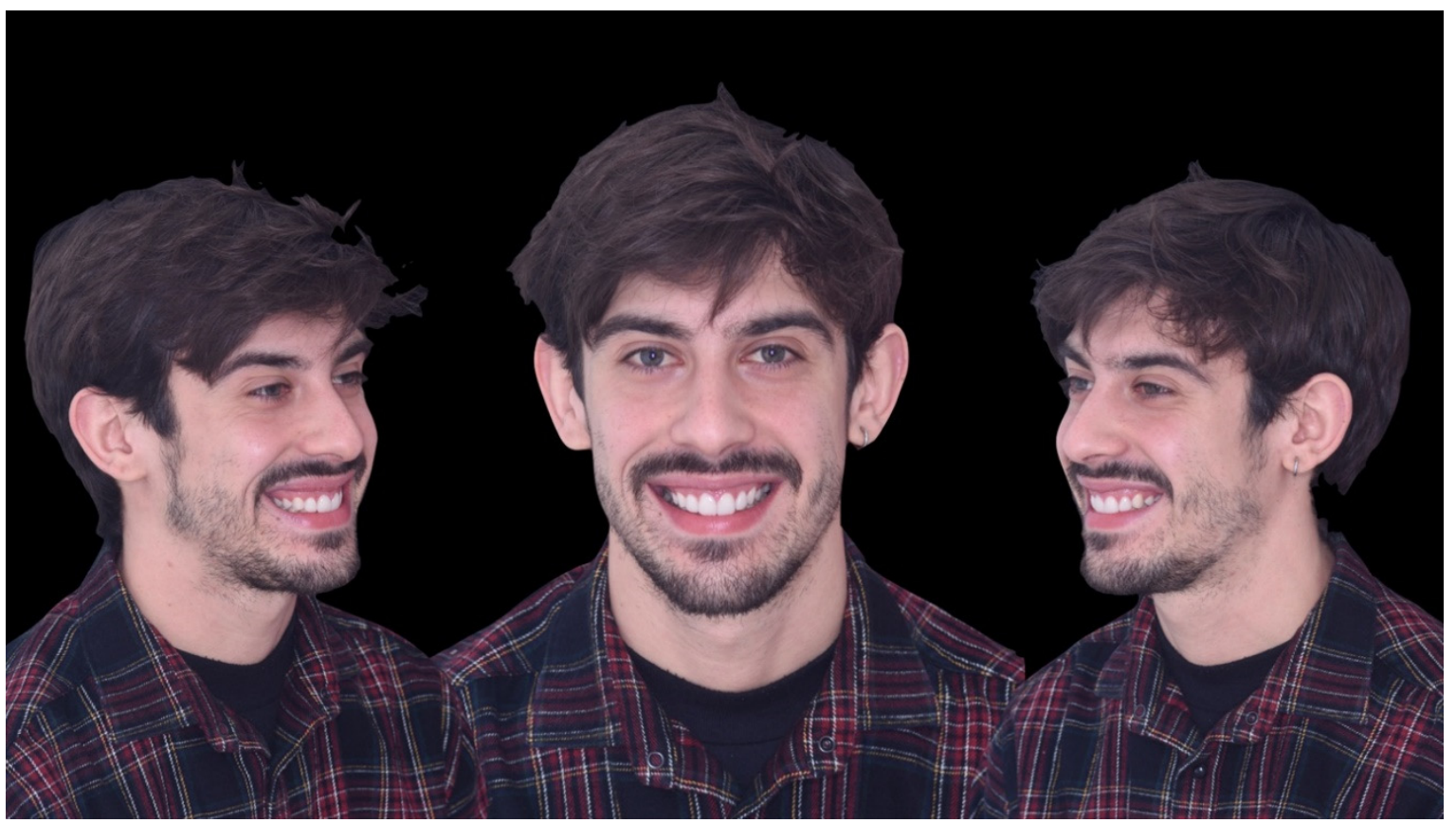

Figure 26. Final treatment.

Bone resective surgery was used to eliminate the altered passive rash.

A digital diagnosis, and therapeutic programming, with a digital plane preview should be the future for clinicians and prosthodontics practitioners. Digital placement offers many benefits to both the clinician and the patient. Today the use of software associated with photo retouching and morphing of digital images (Digital Image Editing) offers the possibility to process the well-customized data and parameters for each specific clinical-aesthetic need of the smile makeover; modern digital technology combined with the experience and aesthetic sensitivity of the dentist is fundamental for the success of the Smile Design, offers greater predictability to the patient, both with regard to the final aesthetic results and the prescribed therapeutic procedure.

\section{Discussion}

The introduction of digital workflows in dentistry has simplified and accelerated the individual work. The aesthetic treatment of the frontal group is the most demanding challenge for the dental team, and it provides a diagnostic framework extended not only to the dental component [1]. The dento-gingival analysis and the mock-up show the altered passive eruption and improve the relationship between the periodontium and the affected dental elements with minimally invasive surgery [8]. According to the aesthetic parameters, the ratio of the length and width of the upper central incisor must be around $85 \%$ and the latter's gingival parabola is $0.5-1 \mathrm{~mm}$ more apical than the lateral incisors. The use of guide masks during the surgical phases allows to control the dental forms, guiding the clinician to remove the least amount of bone [9]. The success of the later steps of the treatment plan depends on the maturation times of the periodontal tissue. If they wait less than 9-12 months to proceed with the prosthetic phase, it could cause an exposure of the prosthetic margin or it can make it "non-cleanable" with the consequent chronic inflammation of the gingival margin. The Digital Smile Design is a helpful tool for the interaction between clinicians and patients in order to evaluate the various treatment options. The visagism of the forms associated with the real potential of the treatment, according to the patient's needs, increases the compliance with the patient [10]. The intraoral scanning has replaced traditional impression techniques by introducing a number of advantages and making the acquired data repeatable and accurate. The management of the scanned file is almost simultaneously with the scan and allows to evaluate the work performed and 
correct it with the patient still in the chair. This kind of work increases the comfort of the patient by reducing chair time [11]. Laboratory procedures can take place directly in a virtual CAD environment and make use of the printing of a stereolithographic model with removable dies. In the specific case provisionals were CAD projects, printed in PMMA and validated on a stereolithographic nylon model, which is the most precise material on the market. During the realization of the final product, the matching with CAD software of the scan of the dental preparation allowed to create a lithium disilicate core that guaranteed the homogeneous layering with two firings of $0.6 \mathrm{~mm}$ of veneering ceramic [12]. By inserting the project in a virtual articulator, it allows a first functionalization of the same according to the centric and eccentric movements; but, even today, it seems necessary to use an analog articulator to reproduce the mandibular movements with more precision [13]. Some laboratory techniques, such as the layering of the veneering ceramic, remain decisive for the aesthetic rendering of the manufact. In this case the die-cast ceramic is chosen because it is more precise than the milled artefacts, and it uses only the stratification of the vestibular portion to implement the aesthetics. In this way, a CAD prototype of the crown structure is made and then subjected to die-casting for lithium disilicate. This material is superior in resistance compared to a normal feldspathic ceramic, since the steep anterior protrusive guide and the possibility of chemical adhesion to the dental substrate is not guaranteed by other materials, such as zirconium oxide [14,15]. Digital Workflow in dentistry could be a useful tool in different fields. These tools could be used in orthodontic treatment after finishing for cosmetic recontouring of the gingival margins with even less invasive methods, such as laser [16].

The resolution of the clinical case in four clinical and two laboratory steps aims to underline the importance of a preliminary study phase of the treatment implemented by a digital workflow.

A different treatment plan for the present case could be an orthodontic one. However, in this case, the patient required to restore his mouth quicker, while usually orthodontic therapy needs a long time to obtain excellent clinical results [17]

\section{Conclusions}

The digital workflow completes traditional clinical and laboratory procedures. In aesthetic rehabilitations, a correct treatment plan and surgical procedures guided by the diagnostic project cannot be ignored. The self-centering geometric preparation, associated to the CAD/CAM techniques for the veneers, allow to obtain predictable results within certain times.

Author Contributions: Conceptualization, M.G.; methodology, G.C.; writing-original draft preparation, G.C.; writing-review and editing, S.L.; visualization, P.S. (Paolo Scattarelli); supervision, P.S. (Paolo Smaniotto); all authors have read and agreed to the published version of the manuscript. Please turn to the CRediT taxonomy for the term explanation. All authors have read and agreed to the published version of the manuscript.

Funding: This research received no external funding.

Conflicts of Interest: The authors declare no conflict of interest.

\section{References}

1. Cervino, G.; Fiorillo, L.; Arzukanyan, A.V.; Spagnuolo, G.; Cicciù, M. Dental Restorative Digital Workflow: Digital Smile Design from Aesthetic to Function. Dent. J. (Basel) 2019, 7, 30. [CrossRef] [PubMed]

2. Jokstad, A. Computer-assisted technologies used in oral rehabilitation and the clinical documentation of alleged advantages-A systematic review. J. Oral. Rehabil. 2017, 44, 261-290. [CrossRef] [PubMed]

3. Agnini, A.; Agnini, A.; Coachman, C. La Rivoluzione Digitale; Quintessenza: Fiorano Modenese, Italy, 2014.

4. Omar, D.; Duarte, C. The application of parameters for comprehensive smile esthetics by digital smile design programs: A review of literature. Saudi Dent. J. 2018, 30, 7-12. [CrossRef] [PubMed]

5. Vandenberghe, B. The crucial role of imaging in digital dentistry. Dent Mater. 2020, 36, 581-591. [CrossRef] [PubMed]

6. Kois, D.E.; Schmidt, K.K.; Raigrodski, A.J. Esthetic templates for complex restorative cases: Rationale and management. J. Esthet. Restor. Dent. 2008, 20, 48-239. [CrossRef] [PubMed] 
7. Mele, M.; Felice, P.; Sharma, P.; Mazzotti, C.; Bellone, P.; Zucchelli, G. Esthetic treatment of altered passive eruption. Periodontol. 2000 2018, 77, 65-83. [CrossRef] [PubMed]

8. Garcia, P.P.; da Costa, R.G.; Calgaro, M.; Ritter, A.V.; Correr, G.M.; da Cunha, L.F.; Gonzaga, C.C. Digital smile design and mock-up technique for esthetic treatment planning with porcelain laminate veneers. J. Conserv. Dent. 2018, 21, 455-458. [PubMed]

9. Levi, Y.L.A.S.; Cota, L.V.S.; Maia, L.P. Digital smile design for gummy smile correction. Indian J. Dent. Res. 2019, 30, 803-806. [PubMed]

10. Rambabu, T.; Gayatri, C.; Sajjan, G.S.; Varma, P.V.K.; Srikanth, V. Correlation between Dentofacial Esthetics and Mental Temperament: A Clinical Photographic Analysis Using Visagism. Contemp. Clin. Dent. 2018, 9 , 83-87. [PubMed]

11. Nagy, Z.; Simon, B.; Mennito, A.; Evans, Z.; Renne, W.; Vág, J. Comparing the trueness of seven intraoral scanners and a physical impression on dentate human maxilla by a novel method. BMC Oral Health 2020, 20, 97. [CrossRef] [PubMed]

12. Chaturvedi, S.; Alqahtani, N.M.; Addas, M.K.; Alfarsi, M.A. Marginal and internal fit of provisional crowns fabricated using 3D printing technology. Technol. Health Care. 2020, 1-8. [CrossRef] [PubMed]

13. Koralakunte, P.R.; Aljanakh, M. The role of virtual articulator in prosthetic and restorative dentistry. J. Clin. Diagn. Res. 2014, 8, ZE25-8. [CrossRef] [PubMed]

14. Hsu, P.; Ramos, V., Jr.; Sadr, A. Microcomputed tomography evaluation of cement shrinkage under zirconia versus lithium disilicate veneers. J. Prosthet. Dent. 2020. [CrossRef] [PubMed]

15. Cosenza, H.; Pamato, S.; Vermudt, A.; Pereira, J.R. Interdisciplinary approach using composite resin and ceramic veneers to manage an esthetic challenge. Prosthet. Dent. 2020. [CrossRef] [PubMed]

16. Borzabadi-Farahani, A. The Adjunctive Soft-Tissue Diode Laser in Orthodontics. Compend. Contin. Educ. Dent. 2017, 38, e18-e31. [PubMed]

17. Maiorana, C.; Speroni, S.; Herford, A.S.; Cicciù, M. Slow Orthodontic Teeth Extrusion to Enhance Hard and Soft Periodontal Tissue Quality before Implant Positioning in Aesthetic Area. Open Dent. J. 2012, 6, 137-142. [CrossRef] [PubMed]

(C) 2020 by the authors. Licensee MDPI, Basel, Switzerland. This article is an open access article distributed under the terms and conditions of the Creative Commons Attribution (CC BY) license (http://creativecommons.org/licenses/by/4.0/). 